\title{
O anticomunismo nos discursos políticos dos anos JK
}

Eliene Gomes da Silva ${ }^{1}$

Resumo: O presente artigo fará uma análise dos discursos políticos do Presidente Juscelino Kubitscheck a fim de perceber a permanência e a reelaboração de um discurso anticomunista que esteve presente no imaginário político e social brasileiro desde os anos 30. Analisaremos o que consideramos uma contradição: a coexistência da imagem cristalizada no imaginário social brasileiro do governo Kubitschek como uma feliz combinação de democracia e desenvolvimento, com práticas autoritárias e conservadoras. Através da Análise de Discurso, pretende-se verificar as novas estratégias discursivas utilizadas durante o governo Kubitschek para referendar um imaginário que negativizava e desacreditava a imagem do comunismo e de seus adeptos.

Palavras chave: Anticomunismo, Análise de Discurso, Imaginário

Abstract: This article analyses President Juscelino Kubitscheck political speeches to distinguish the maintenance and re-elaboration of an anti-communist discourse present in the Brazilian social and political mentality since the thirties. It will be analyzed what we considered a contradiction: the coexistence of a crystallized image in Brazilian social mentality in Kubitschek government as a well-succeeded combination among development and democractical, autocratical and conservative praxis. This work intends to verify new discourse strategies used in Kubitschek government to reassure a mentality that denied and denigrated communism image and its supporters.

Key words: Anti-communism, Discourse Analisys, Collective Mentality 


\section{O anticomunismo e o governo JK}

(...) em toda sociedade a produção do discurso é ao mesmo tempo controlada, selecionada, organizada e redistribuída por certo número de procedimentos que têm por função conjurar seus poderes e perigos (...) (FOUCAULT, 1996).

Visto como uma frente heterogênea composta por grupos políticos e sociais de projetos diversos, além de um amplo espectro ideológico que reúne reacionários, conservadores, liberais e até esquerdistas, o anticomunismo no Brasil vestiu-se de diferentes roupagens e esteve presente no imaginário político e social brasileiro até atingir seu ponto máximo com o golpe militar de 1964.

No que tange ao imaginário popular, o período em que o Brasil foi governado pelo presidente Juscelino Kubitschek de Oliveira (janeiro de 1956 a janeiro de 1961) é visto como "os anos dourados", uma época marcante na História do Brasil. Denominado de nacional desenvolvimentista, os anos JK caracterizaram-se por um apelo ao senso de nacionalismo contra o subdesenvolvimento e as injustiças sociais. $\mathrm{O}$ grande arranco desenvolvimentista, aliado a políticas de estímulo à industrialização resultaram em altas taxas de crescimento. Por outro lado, crescia também a inflação e o endividamento externo. Porém, foram os elementos positivos que ficaram gravados na memória coletiva nacional. Quase cinco décadas após o término do seu mandato ainda é comum a utilização da imagem de JK como líder incontestável e modelo de político a ser seguido.

Para Thomas Skidmore (1982: 210), Kubitschek cercou-se de símbolos e estratégias a fim de ganhar a simpatia das diferentes classes políticas e sociais. Em primeiro lugar, esforçou-se por gerar um senso de confiança entre os brasileiros afirmando sua fé no processo democrático e na industrialização como formas de superar o subdesenvolvimento. E ainda:

Kubitschek esforçou-se também para tranqüilizar os fanáticos anticomunistas nas Forças Armadas, através de repetidas declarações anticomunistas e sua política exterior ortodoxa. Não se desviaria, por exemplo, do tradicional apoio brasileiro a Portugal, e foi receptivo em seguir a liderança americana na diplomacia hemisférica, pelo menos no seu aspecto anticomunista. (...) Não havia ingredientes 
antiamericanistas, nem ataques ao "imperialismo" (SKIDMORE, 1982: 209).

O principal símbolo escolhido por Kubitschek foi a implantação da capital no interior do país. A construção de Brasília processou-se num clima de expectativas, mobilizando brasileiros de todas as classes que viam em sua construção o sinal de novos tempos para o Brasil. Além disso, tal empreitada contribuía para desviar a atenção de uma série de problemas nos setores econômicos e sociais.

Contando com um aparelho de Estado já montado no governo de Getúlio Vargas, especialmente no último mandato, Kubitschek valeu-se do planejamento e dos corpos técnicos que o Brasil havia formado para pôr em marcha um plano de governo que lhe daria notoriedade. Soube dar legitimidade política às suas ações, prestigiando as instituições representativas e domesticando os descontentamentos militares. Em discurso afirmava que em seu governo faria um esforço na preservação da

manutenção do princípio da autoridade, a preservação da dignidade do poder "legitimamente constituído", [não permitindo] "provocações perigosas", "que se intriguem impunemente as Forças Armadas" (...) contribuindo para o estabelecimento da desordem (...) abrindo novas possibilidades para que sejam feitas novas vítimas, a que jorre mais sangue, a exemplo do que aconteceu em 27 de novembro de 1935 (KUBITSCHECK, 1956: 32). ${ }^{2}$

O lema "desenvolvimento e ordem", adotado nos primeiros dias de governo, aliado a uma série de atitudes anticomunistas e a uma política externa ortodoxa agradaram as Forças Armadas. Kubitschek usava uma linguagem nacionalista e procurava convencer os militares que não permitiria que os radicais da esquerda ou da direita tirassem o Brasil do caminho democrático. Democracia aí entendida como o respeito à ordem e à lei.

Desde o fim do Estado Novo e durante o efêmero processo democrático que o país vivenciou, de 1945 com a eleição de Dutra até o golpe militar de 1964, houve uma tentativa de se firmar a imagem da democracia pela construção de um seu oposto, numa dualidade excludente que opunha democracia e desordem; logo, opunha também democracia e comunismo. Esse discurso que associava comunismo à desordem, tão alardeado durante o Estado Novo, também foi bastante utilizado no governo Dutra servindo inclusive de pretexto para a cassação do registro do PCB em maio de $1947^{3}$. 
O discurso da ordem que apresentava a democracia como uma imagem unificadora, integradora da nacionalidade, também foi amplamente utilizado no governo Kubitschek. Contraditoriamente ao discurso da democracia e liberdade política, o PCB manteve-se na ilegalidade durante os "anos dourados." "Em passagem por Washington, em janeiro de 1956, o presidente Juscelino Kubitschek prometera ao Senado estadunidense que não legalizaria o partido" ${ }^{4}$ (GORENDER, 2002).

Essa, entre outras atitudes do governo Kubitschek, compromete a imagem mantida no imaginário popular e político brasileiro de que seu governo tenha sido uma feliz combinação de desenvolvimento econômico e democracia. Tais atitudes, aparentemente contraditórias, como por exemplo a ordem de Kubitschek para o fechamento do Sindicato dos Trabalhadores Portuários e da Liga de Emancipação Nacional em junho de 1956, ambos comandados por comunistas, tornam-se compreensíveis quando as analisamos enquanto constituintes de um imaginário político e social anticomunista que permitiu a coexistência de elementos marcadamente autoritários durante um governo que tinha a democracia como sua principal bandeira (Cf. SKIDMORE, 1982: 213).

Episódios anticomunistas como esses, reproduzidos durante décadas, podem ser analisados como elementos de uma tradição, reorganizados para se articular as diferentes práticas e posições, podendo adquirir novos significados e relevância. A continuidade de tal tradição permitiu a permanência de um imaginário anticomunista que se mostrou mais agudo em momentos de exceção, mas que permaneceu vivo e atuante mesmo em períodos de pleno funcionamento da democracia, como os anos Kubitschek. Na análise de Marcos Gonçalves, o imaginário anticomunista operava através da clássica fórmula dicotômica que opunha democracia ocidental versus ditadura comunista (Cf. GONÇALVES, 2004: 20).

A capacidade de reatualização do anticomunismo, bem como a permanência de certos elementos, permite-nos analisar o anticomunismo como uma "representação que carrega sentidos ocultos, que construídos social e historicamente, se internalizam no inconsciente coletivo" (PESAVENTO, 2003: 41) cristalizando efeitos de sentidos que contribuíram para a construção de uma posição política e social de "consenso" acerca do comunismo e dos comunistas. Este "consenso" é validado pelo que Eni P. Orlandi (2001: 31) chama de interdiscurso 
aquilo que fala antes, em outro lugar, independentemente (...) um jádito que sustenta a possibilidade mesma de todo o dizer [ou seja], todo o conjunto de formulações feitas e já esquecidas que determinam o que dizemos. Para que minhas palavras tenham sentido, é preciso que elas já façam sentido.

O governo de Juscelino Kubitschek valeu-se largamente desse interdiscurso, principalmente no que tange ao comunismo e à necessidade de combatê-lo. E as condições sócio-históricas e ideológicas de produção que possibilitaram a emergência de determinados sentidos e não de outros, tornam-se objeto de análise imprescindível para a compreensão do período Kubitschek. Foi tentando procurar "o não-dito naquilo que [foi] dito" (ORLANDI, 2001: 32) que os discursos políticos proferidos durante os anos Kubitschek foram analisados.

As representações fazem parte de uma dinâmica social que não se reduz a elementos físicos, materiais ou racionais, já que se realizam numa rede de sentidos fixados pela sociedade simbolicamente. Dessa forma, cabe analisar como essas representações são construídas e acionadas estrategicamente (ou não) no seio de uma determinada configuração social, contribuindo para a fabricação de afetos, identificações, repulsas e paixões, indispensáveis para a construção e consolidação de uma determinada tradição. (Cf. ANSART, 1977: 22)

\section{O Anticomunismo nos discursos políticos de Kubitschek}

O imaginário anticomunista no Brasil foi uma expressão política eficaz notadamente nos períodos que antecederam os golpes do Estado Novo e o Golpe Militar de 1964. Vários estudos dão ênfase a esses períodos. Entretanto, podemos perceber que, ao contrário do que afirmam alguns autores, o imaginário anticomunista brasileiro não ocupou papel secundário no cenário político brasileiro nos anos Kubitschek. Valendo-se do interdiscurso, tal expressão política se manteve viva e atuante durante os "anos dourados", às vezes com uma nova "roupagem" e em outros casos utilizando elementos de uma tradição que começou a se estruturar após a Intentona Comunista de 1935 e que nos anos Kubitschek já estava perfeitamente consolidada.

Desde a campanha para a presidência da República em 1955, a oposição insistia em associar a candidatura de Kubitschek aos comunistas. A indicação de Kubitschek deu ocasião ao recrudescimento de sentimentos antigetulistas e contraditoriamente 
anticomunistas. A indicação de João Goulart para vice-presidente assustou a oposição e contrariou parte da oficialidade das Forças Armadas. Porém, a aliança PSD-PTB e um discurso focalizado na necessidade de aceleração da industrialização atrairam setores da classe média e de muitos oficiais da Forças Armadas, ansiosos de que o Brasil se mantivesse na trilha constitucional. Em 3 de outubro de 1955, Juscelino Kubitschek foi eleito presidente com 3.077.411 votos e João Goulart, vice, com uma votação superior a de Kubitschek, 3.591.409 votos (Cf. SKIDMORE, 1982: 186).

Eleito com uma percentagem de $36 \%$ dos votos, Kubitschek passou a enfrentar uma oposição acirrada por parte de alguns setores golpistas que tentaram a todo custo impedir a sua posse. Carlos Lacerda ${ }^{5}$, em seu jornal Tribuna da Imprensa, apelava para "quem tem nas mãos a força capaz de decidir a questão (...) ouçam a voz do seu patriotismo e não a dos que falam em legalidade (...) foram os comunistas que elegeram Kubitscheck e Goulart" (LACERDA, 1955: 188).

A luta entre golpistas e o campo pró-legalidade atingiu o auge quando, em 11 de novembro, unidades do Exército comandadas pelo General Lott, ex-Ministro da Guerra, ocuparam todos os principais prédios públicos, estações de rádio, jornais e cercaram as bases aéreas e navais dissidentes num "golpe preventivo" que depôs o Presidente interino Carlos Luz, acusado de estar ligado aos golpistas. O presidente do Senado, Nereu Ramos, foi eleito para a presidência enquanto as forças anti-Vargas reclamaram da “injustificada interrupção do processo legal” (SKIDMORE, 1982: 195).

Após inúmeras conspirações, golpes e contragolpes, o presidente Juscelino Kubitschek e o vice João Goulart assumiram a presidência do Brasil esforçando-se para demonstrar que o temor de seus inimigos era infundado. Para isso Kubitschek contou com o apoio de partidários como, por exemplo, o Arcebispo de Diamantina, Dom José Newton de Almeida Batista ${ }^{6}$, que em comunicado à imprensa refutava as acusações de que Kubitschek teria ligações com os comunistas.

Contra esse ilustre diamantinense surge grave acusação e conseqüente desconfiança. Trata-se do apoio comunista, a encerrar duplo aspecto: o do falado acordo com os vermelhos, e o das convicções pessoais do acusado. Quanto ao primeiro aspecto (...) será, pois, desleal e até criminoso insistir na acusação, a menos que se apresentem provas cabais. Sobre a pessoa do acusado (...) se trata de cidadão nascido, educado e vivido no espírito e na observância da Religião Católica. Nesse ponto ele é bom mineiro, filho do próprio coração de Minas. 
Em sua vida privada e pública colhem-se inúmeras provas de sua fidelidade e de sua dedicação à Igreja.

Nas palavras do Arcebispo percebemos claramente representações anticomunistas que tomam como base as matrizes de fundamentação católica. $O$ representante da Igreja considerava como "criminosa" qualquer associação com os comunistas e assegura que como "bom mineiro" o candidato à presidência Juscelino Kubitschek não tinha nenhuma relação com “os vermelhos”, pois era fiel aos preceitos da Igreja.

O discurso do Arcebispo utiliza inúmeras representações construídas durante décadas sobre os comunistas. Percebemos a eficiência do interdiscurso que Orlandi (2001: 31) caracteriza como um "saber discursivo que torna possível todo dizer e que retoma sob a forma do pré-construído, o já-dito que está na base do dizível, sustentando cada tomada da palavra." A naturalização do interdiscurso nos remete àquilo que Tânia Navarro (1994: 49), citando Castoriadis (1995), chamou de "imaginário instituinte", que bloqueia a possibilidade de se pensar o heterogêneo, criando a noção de "evidente", "natural". O outro passa a ser visto enquanto cópia imperfeita no domínio da identidade coletiva.

Durante os anos Kubitschek percebe-se a manutenção e naturalização desse imaginário instituinte. $\mathrm{O}$ fato de $\mathrm{o} \mathrm{PCB}$ ter sido mantido na ilegalidade no governo Kubitschek confirma e reforça os sistemas instituídos. Para Orlandi trata-se da institucionalização do sentido dominante; ou seja, o sentido oficial de onde decorre a legitimidade (ORLANDI,1992 APUD NAVARRO, 1994: 50).

A conturbada campanha eleitoral que elegeu Kubitschek e Jango nos dá o tom da confusa vida política do país no início dos anos 50. A estabilidade política dos anos Kubitschek deveu-se, entre outros fatores, à coesão nas Forças Armadas sob a autoridade do Ministro Lott e à atuação do Congresso, através da aliança PSD/PTB. Ambos atuaram de maneira convergente no sentido de apoiar a política econômica, cujo núcleo era o Programa de Metas (Cf. BENEVIDES, 1979: 28).

Na análise de Amado Cervo (1994: 30), Kubitschek adotou um modelo de desenvolvimento aberto que oscilava entre o nacionalismo e o liberalismo, permitindo uma atuação mais livre no que diz respeito aos órgãos financeiros internacionais, como o FMI e o Banco Mundial. A aproximação ideológica com os Estados Unidos facilitava 
a recorrência ao capital estrangeiro, tão necessária ao desenvolvimento econômico. Brasil e Estados Unidos compunham uma "aliança militar defensiva" apoiada num forte discurso anticomunista.

Mesmo antes de tomar posse, Kubitschek visitou diversos países com o intuito de legitimar sua eleição e assegurar investimentos estrangeiros, levando sempre em consideração a postura adotada pelo Brasil no cenário da Guerra Fria. Em discurso no Senado norte-americano, Kubitschek garantia que "o nosso governo seguirá normas políticas similares às dos Estados Unidos no que se refere à situação política mundial (...), não queremos que nenhuma ideologia extremista domine a nossa pátria". .

Para Cervo (2001: 114),

seria, contudo, um erro atribuir à ação norte-americana o anticomunismo latino, visto que a tradicional opinião liberal e cristã repugnava a ideologia marxista (...). Em meio às pressões externas oriundas de Moscou e de Washington, entre o liberalismo e o comunismo, a América Latina inclinava-se para o lado ocidental (...).

Além dos Estados Unidos, Kubitschek visitou a Holanda, Bélgica, Inglaterra, Luxemburgo, França, Alemanha, Itália, Vaticano e Espanha a fim de angariar investimentos estrangeiros para pôr em prática o Plano de Metas. Em um balanço sobre a viagem (KUBITSCHEK, 1962: 36) comentou:

Aos chefes de Estado, aos capitães da indústria e do comércio dos vários países que visitei, apresentei as bases da política de desenvolvimento programada para fazer "50 anos em 5" e expus os modos de cooperação que desejava para a técnica e o capital exteriores.

Em seus discursos nesses países, Kubitschek procurava atrelar o tema ideológico do comunismo ao tema político do subdesenvolvimento como forma de "garantir a sobrevivência da civilização ocidental." (Ibidem: 83)

Em discurso na Companhia Siderúrgica de Volta Redonda ${ }^{8}$, em companhia do vice-presidente dos Estados Unidos, Richard Nixon, no dia 3 de fevereiro de 1956, um mês após a sua posse, Kubitschek já utilizava uma retórica marcadamente anticomunista e enfatizava a história de amizade e colaboração entre o Brasil e os países ocidentais, especialmente os Estados Unidos. 
A luta em defesa do estilo de vida que adotamos, da nossa índole cristã, de nosso amor à liberdade e à democracia, é que está exigindo que o Brasil utilize e transforme as suas reservas minerais e as suas matérias primas (...). Temos uma luta comum, os Estados Unidos da América e o Brasil, que o nosso visitante, senhor Richard M. Nixon, bem conhece; essa luta visa a impedir o advento do império da opressão; é a luta em favor da liberdade no mundo. Não há meio mais certo de enfrentar o inimigo da democracia do que suprimir-lhe os argumentos. Melhorar o nível de vida do povo é a grande arma pela democracia (KUBITSCHEK, 1956: 22).

Com vistas a atrair os investimentos estrangeiros ${ }^{9}$, Kubitschek adotou o discurso anticomunista pregado pelos EUA, deixando clara quais seriam as diretrizes de governo em relação ao comunismo e à Guerra Fria. Para isso valeu-se largamente de um imaginário anticomunista de matriz católica, nacionalista e liberal, numa reprodução de representações construídas no Brasil desde os anos 30. Porém, enquanto nos anos trinta a construção do imaginário anticomunista necessitava deixar claro o "inimigo" que se desenhava, nos anos cinqüenta o interdiscurso se encarregava de identificá-lo.

Em 1958 o presidente Kubitschek lançou a Operação Pan-Americana, tentando unir as aspirações norte-americanas de segurança e combate ao comunismo e o desenvolvimento dos países da América Latina, especialmente o Brasil.

O objetivo principal da OPA era promover uma mudança na política dos Estados Unidos com relação à América Latina, para que aquele país realmente incentivasse a industrialização e colaborasse com a integração do continente, dando novo sentido à diplomacia brasileira, as novas demandas impostas pelo projeto desenvolvimentista. Uma característica essencial da OPA foi dar aos problemas econômicos um sentido eminentemente político. Nas palavras do diplomata Celso Antônio de Souza e Silva $(1959)^{10}$,

(...) as populações americanas mergulhadas na miséria, doença e ignorância, são um peso morto para o mundo ocidental e sujeitas às infiltrações das mais indesejáveis ideologias; [faz-se necessário buscar] as soluções dos problemas econômicos básicos na América, não mais no limitado campo técnico- econômico, mas no mais alto nível político.

O lançamento da OPA tornou visível as diretrizes anticomunistas adotadas pelo governo Kubitschek, que não apareceram claramente durante a campanha eleitoral 
devido, entre outros fatores, ao apoio dado pelos comunistas à campanha de Kubitschek. Nos discursos referentes à política externa e desenvolvimento econômico, o binômio "mundo ocidental x comunismo" tornou-se cada vez mais freqüente, além do apoio do Brasil aos Estados Unidos no contexto da Guerra Fria. Nas palavras de Kubitschek (1959: 11), “não deverá o Brasil, em caso algum, deixar de solidarizar-se com os interesses vitais das Nações Americanas, a que o ligam poderosos vínculos geográficos, históricos, políticos e culturais."

Em discurso no Senado norte-americano, o presidente afirmava ainda que participara das últimas duas guerras do lado da América do Norte, não apenas por solidariedade continental, "mas por comungarmos nos mesmos ideais, nos mesmos sentimentos, no mesmo respeito à eminente dignidade do homem" (KUBITSCHEK, 1959: 37).

Em 1958, numa visita do vice-presidente Richard Nixon aos países da América Latina, ocorreram inúmeras manifestações populares antiamericanas. Nixon foi insultado no Peru e atacado na Venezuela por uma multidão furiosa. Dwight Eisenhower mobilizou tropas para um eventual desembarque e resgate de Nixon em Caracas, gerando uma onda de protestos políticos em todo o continente. Aproveitandose das circunstâncias, Kubitschek enviou uma carta ao presidente dos EUA lamentando a deteriorização das relações hemisféricas e propondo uma revisão do panamericanismo. Nas palavras de Kubitschek (1958) era imprescindível não deixar que os protestos decorrentes da viagem de Nixon deixassem

(...) a impressão de que nos desentendemos em nosso continente. A propaganda dos interessados no anti-americanismo, naturalmente, procura agora converter esses supostos desentendimentos numa incompatibilidade, mesmo numa inimizade entres países livres da comunidade americana; o que, felizmente, está bem longe de se verificar, (...) não é justo que perdure essa impressão que enfraquece moralmente a causa da democracia, em cuja defesa estamos empenhados. ${ }^{11}$

Levando em conta que os EUA estavam muito mais preocupados com o combate à subversão comunista do que com o desenvolvimento latino-americano, a OPA construiu uma proposta de desenvolvimento econômico aliado à promoção da "segurança hemisférica" e dessa forma se adequou melhor ao contexto bipolar daquele 
momento. Os discursos do presidente Kubitschek estão inseridos nestas condições de produção; ou seja, fazem parte do contexto imediato de enunciação que pode ser sóciohistórico, ideológico e/ou imaginário, sendo parte da formação discursiva dominante no período (BENEVIDES, 1979: 236).

O primeiro passo para o lançamento da OPA foi uma carta enviada por Kubitschek ao presidente dos Estados Unidos, Dwight Eisenhower. O principal objetivo da carta era captar recursos em larga escala para projetos de desenvolvimento econômico e colocar o Brasil em posição de liderança com relação aos países latinoamericanos, tendo a superpotência americana como fonte de recursos. Desta forma, o projeto nomeado de Operação Pan-Americana reverteu-se de aspectos ideológicos, deixando clara a posição do Brasil diante da questão comunista. A principal questão levantada por Kubitschek (1958) na carta enviada a Eisenhower era a seguinte: "Estaremos todos nós, é a hora de nos perguntar, agindo no sentido de se estabelecer a ligação indestrutível de sentimentos e interesses que a conjuntura grave aconselha e recomenda?"

Um mês depois, Kubitschek (1958) explicava a questão levantada pela carta:

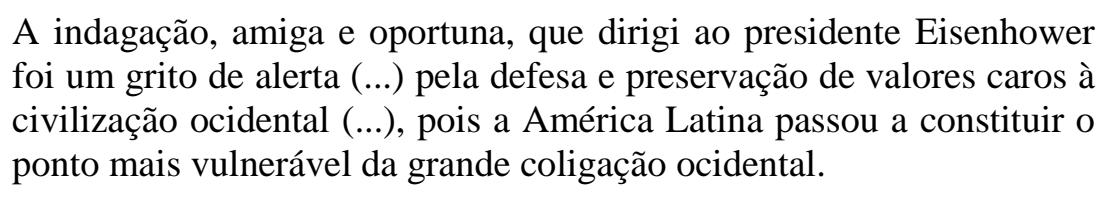

E ainda, "Deus sabe, porém, que os Estados Unidos (...) têm sede de justiça pela sua contribuição em favor da liberdade do mundo."

Em resposta a Kubitschek, o presidente dos EUA reafirmava a necessidade de combater os comunistas" ${ }^{12}$ : "Vossa Excelência caracterizou de maneira exata tanto a situação atual como a conveniência de medidas corretivas. Estou, por isso mesmo, encantado de que Vossa Excelência haja tomado a iniciativa nesse assunto."

O presidente Kubitschek (2002: 197) tentava mostrar aos EUA que a sua preocupação com o desenvolvimento estava diretamente relacionada à questão do comunismo. A opinião de Kubitschek sobre as manifestações sofridas por Nixon era a seguinte:

De fato, os comunistas haviam liderado as manifestações; mas, se o povo da Venezuela e do Peru estivesse satisfeito com os Estados 
Unidos, o apelo dos comunistas teria caído no vazio. O que se vira fora justamente o contrário: uma enorme massa popular deixar-se levar por uma reduzida minoria comunista. E por que isto acontecera? Justamente porque o apelo dessa minoria encontrara as massas psicologicamente indispostas em relação aos Estados Unidos.

A partir do lançamento da OPA, questões como a "ameaça comunista" e a possibilidade de infiltração de "ideologias extremistas" foram mecanismos comumente usados nos discursos políticos de Kubitschek. Palavras como "democracia", "segurança", "desenvolvimento", "liberdade" e "ordem" passaram a ser largamente utilizadas para a produção de efeitos ideológicos específicos. Na análise de Pêcheux (1995: 161), palavras e expressões podem mudar de sentido segundo as posições ocupadas por aqueles que as empregam, adquirindo sentido em referência às formações ideológicas nas quais essas posições se inscrevem, dando força e legitimidade à sua fala.

Desta forma, os discursos políticos de Kubitschek podem ser incluídos no que Marilena Chauí (1989: 10) denominou de "discurso competente": aquele que pode ser proferido, ouvido e aceito como verdadeiro ou autorizado. Um discurso instituído onde a linguagem sofre certa restrição, mas o conteúdo e a forma já estão previamente autorizados.

Para Michel Foucault (1996:09),

(...) em toda sociedade a produção do discurso é ao mesmo tempo controlada, selecionada, organizada e redistribuída por certo número de procedimentos que têm por função conjurar seus poderes e perigos, dominar seu acontecimento aleatório, esquivar sua pesada e temível materialidade (...). Qualquer um, enfim, não pode falar qualquer coisa.

O caráter anticomunista do governo Kubitschek pode ser percebido em uma série de discursos, o que nos leva a afirmar que nos "anos dourados", período tido como um dos mais democráticos da política brasileira antes de 1964, o imaginário anticomunista manteve sua atuação contando com mecanismos mais "sutis", mas não menos eficazes. A utilização de uma série de matrizes anticomunistas aparecem claramente num discurso proferido por Kubitschek em 20 de junho de 1958:

Creio chegada a hora de um pronunciamento claro e sincero do Brasil [sobre] o que pensa no debate que se vem travando entre as forças que, dividindo o mundo, se defrontam, se ameaçam, e ora se aproximam, ora se afastam, transformando a época em que vivemos 
num tecido de inquietações e sobressaltos (...) que põe em permanente perigo a existência das sociedades humanas, uma vez que estão em jogo necessariamente também os nossos interesses mais vitais. ${ }^{13}$

O discurso de um perigo iminente, bastante utilizado, ajudava a criar um clima de insegurança que de certa forma legitimava atitudes anticomunistas. Além disso, a luta entre o bem e o mal reforçava no imaginário social a visão maniqueísta da sociedade. Corroborada pela Igreja Católica e reforçava a "demonização" do comunismo e conseqüentemente a necessidade de combatê-lo pelo bem da família, da propriedade, da moral e da religião; enfim, dos "nossos interesses mais vitais."

Num balanço sobre a Operação Pan-Americana, o presidente Kubitschek (1962: 173) enfatizava: “A Operação Pan-Americana (...) não visou apenas a combater adversários ideológicos, evitar infiltração insidiosa em nossos territórios; mas também, e sobretudo, objetivou uma solução para a crise do nosso tempo."

Cuidadosamente, o presidente Kubitschek evitava dar nomes aos "adversários ideológicos", preferindo valer-se do silêncio como forma de atribuição de sentidos. Dessa forma, não temos como afirma Orlandi (1992: 13), "nem um sujeito tão visível, nem um sentido tão certo." Mas como "o dizer tem relação com o não-dizer" (ORLANDI, 2001: 82), os discursos de Kubitschek encaixam-se num interdiscurso, ideologia e formação discursiva que nos levam a afirmar que "há sempre no dizer, um não-dizer necessário" (Idem).

Em agosto de 1958, o Secretário de Estado norte-americano Foster Dulles, em visita ao Brasil, participou de inúmeras reuniões realizadas no Itamaraty com o objetivo de "promover a assinatura de um convênio visando à extirpação dos focos de fermentação ideológica na América Latina" (KUBITSCHEK, 2002: 203).

Apesar de saber que a questão do comunismo era o "item principal" e "problema prioritário" dos Estados Unidos, Kubitschek insistia na necessidade de reformular o pan-americanismo dando-lhe uma feição prática, reforçando o que já havia dito em carta ao presidente Eisenhower:

Difícil é difundir o ideal democrático e proclamar a excelência da iniciativa privada no mundo, quando em nosso hemisfério predominam condições econômico-sociais, reflexos do subdesenvolvimento, conducentes ao estatismo. E também não é justo (...) que nos declaremos dispostos a lutar pela moral cristã, se não 
fizermos um esforço conjunto no sentido de erradicar o sofrimento que pesa sobre tantas vidas. ${ }^{14}$

Nos discursos proferidos por Kubitschek e posteriormente, num balanço que o mesmo fez de seu governo, podemos perceber que embora o comunismo não pareça ser sua maior preocupação pessoal, o tema, bem como as possíveis diretrizes anticomunistas a adotar, estava na "ordem do dia", interferindo em todas as negociações, principalmente no que se referia à política externa.

Valendo-se de uma das formas do silêncio que trabalha com a estratégia de um sujeito "não tão visível" e usando uma retórica anticomunista de matriz liberal, Kubitschek ressaltava a "excelência da iniciativa privada no mundo", uma vez que "todo estatismo é por definição antiliberal” (MARTINHO, 2000: 156), pois destrói a "propriedade", a "moral cristã" e atenta contra a "liberdade." Através de um discurso que exaltava o seu oposto, o presidente criticava o comunismo enquanto forma de governo, utilizando largamente o interdiscurso e o silêncio. Este último é caracterizado por Orlandi (2001:83) como "silêncio constitutivo", pois uma palavra apaga outras palavras, ou seja, "para dizer é preciso não-dizer." Desta forma, o "inimigo" a que o presidente se referia sem se mostrar:

Consentir que se alastre o empobrecimento nesse hemisfério é enfraquecer a causa ocidental. Não recuperar, para um nível de vida compatível com os foros da dignidade humana, criaturas que englobamos na denominação de povos irmãos, é semear males em terreno propício para as mais perigosas germinações. ${ }^{15}$

Ao enfatizar a "causa ocidental", fica claro que o capitalismo e a democracia seriam as únicas formas de governo capazes de trazer "dignidade humana" e que o oposto do capitalismo, o oposto do "bem" traria o "mal", fruto de "perigosas germinações." Aparece aí a visão maniqueísta reproduzida por um anticomunismo de matriz católica que desenhava um mundo marcado pela eterna luta entre o "bem" e o "mal."

Curiosamente, nos discursos de Kubitschek encontramos elementos provenientes de representações anticomunistas dos anos 30 que se reatualizaram e se adequaram a um novo contexto, o que nos permite captar linhas de permanências e continuidades presentes ao longo da história. Além disso, nos discursos políticos de Kubitschek 
verificamos o que Orlandi (2001:35) denomina de "esquecimento da ordem do inconsciente", resultante do modo pelo qual somos afetados pela ideologia, "temos a ilusão de ser a origem do que dizemos quando, na realidade, retomamos sentidos préexistentes." (Ibidem: 36) Ao reproduzir determinados discursos,

Os sujeitos esquecem que [aquele sentido] já foi dito (...) para, ao se identificarem com o que dizem, se constituírem em sujeitos. É assim que suas palavras adquirem sentido, é assim que eles se significam retomando palavras já existentes como se elas se originassem neles e é assim que sentidos e sujeitos estão sempre em movimento, significando sempre de muitas e variadas maneiras. Sempre as mesmas mas, ao mesmo tempo, sempre outras. (Idem)

Assim, ao analisarmos as condições de produção as quais os discursos políticos de Kubitschek estão inseridos, percebemos a confluência de relações de força e de sentido, na medida em que "não há discurso que não se relacione com outros, [assim como] o lugar a partir do qual fala o sujeito é constitutivo do que ele diz"(Ibidem: 35). Não podemos esquecer também que os mecanismos que possibilitam o funcionamento dos discursos são atravessados por formações imaginárias, o que nos permitem afirmar que não são os sujeitos e seus lugares empíricos que funcionam no discurso, mas suas imagens, resultados de projeções (Ibidem: 40).

$\mathrm{Na}$ análise de Bronislaw Baczko (1985: 298), as ações e as imagens delas resultantes são guiadas por representações que modelam os comportamentos, mobilizam as energias e legitimam as violências. Passa-se a exercer, então, um poder simbólico que reforça e duplica a dominação efetiva, garantindo a obediência pela conjugação das relações de sentido e poderio. Porém, como analisa Foucault (1996: 10), o poder está disseminado por todas as partes do mundo social, numa trama complexa e heterogênea de relações, na qual as resistências a ele também tomam parte e têm papel determinante. $^{16}$

Dessa forma, o imaginário anticomunista nos anos Kubitschek é visto como uma representação já construída social e historicamente e que aos poucos foi se internalizando no inconsciente coletivo, num processo de naturalização que produz evidências e oculta os efeitos ideológicos. Tal imaginário torna-se evidente nos discursos políticos à medida que o discurso "funciona de modo a assegurar a permanência de uma certa representação (...) numa articulação necessária e sempre 
presente entre o real e o imaginário" (ORLANDI, 2001: 73), entre a linguagem e a ideologia.

Tal articulação torna-se evidente no discurso de Kubitschek proferido às Forças Armadas no dia 17 de junho de 1958, ainda sobre a Operação Pan-Americana:

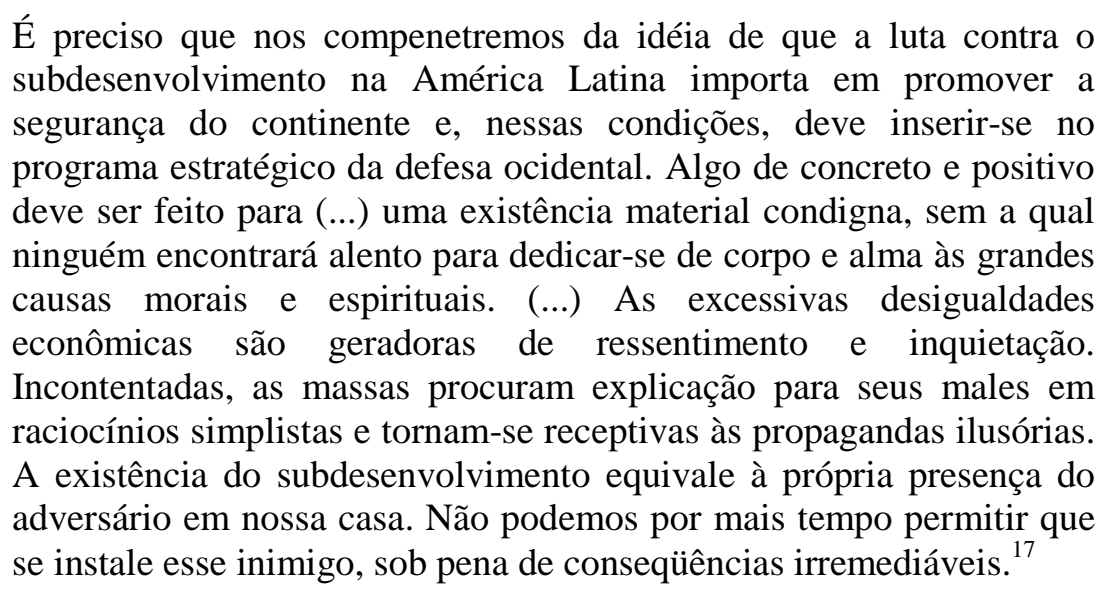

$\mathrm{Na}$ exposição de Kubitschek, o anticomunismo é evidente à medida que o mesmo recorre a diferentes matrizes na tentativa de justificar a necessidade da implementação de seu projeto político. Ao tratar da "segurança", "defesa ocidental", "adversário" e "inimigo", encontramos nitidamente um anticomunismo de matriz nacionalista que enfatizava a defesa da nação vista como intocável. O comunista era visto como o "outro" e, portanto, "adversário" e "inimigo" devido principalmente às suas posições internacionalistas.

Ao tratar da defesa das "grandes causas morais e espirituais", Kubitschek recorre a representações anticomunistas de matriz católica, "uma vez que os comunistas eram apresentados como adversários irreconciliáveis da moralidade cristã tradicional." (MOTA, 2002: 62) Na análise de Rodrigo Mota (ibidem: 60-70), boa parte das preocupações dos anticomunistas voltava-se para a preservação da moral sexual e da estrutura familiar, que a pregação subversiva estaria colocando em risco. Nesse caso, o foco das atenções voltava-se para a União Soviética que, além de ser fonte de inspiração ao comunismo mundial, passara por transformações políticas, econômicas e também comportamentais como, por exemplo, o divórcio, a libertação da mulher, a educação sexual e o aborto. Daí derivaram as acusações do anticomunismo brasileiro, que apresentavam os comunistas como sedutores, devassos e inimigos da família. 
A Igreja Católica se empenhou em reforçar tal imagem acerca dos comunistas. Nas palavras do bispo de Diamantina, Dom Geraldo de Proença Sigaud, “(...) o comunismo ensina a dissolver as famílias, a violentar as mulheres dos povos que não são comunistas e a respeitar as 'famílias' dos que são". ${ }^{18}$

A associação entre subdesenvolvimento e subversão também era recorrente nos discursos de Kubitschek. Fosse para atrair os investimentos norte-americanos ou por uma questão ideológica pessoal, Kubitschek defendia a idéia de que o regime democrático só vigoraria em países que se afirmavam economicamente. Sua defesa do crescimento econômico, da industrialização, do progresso; enfim, do capitalismo, se inseria numa formação discursiva e conseqüentemente ideológica já dada, "que determina o que pode e deve ser dito.” (ORLANDI, 2001: 43)

\section{Considerações Finais}

A análise dos discursos políticos que circularam nos anos Kubitschek nos permite afirmar que os aspectos econômicos, que eram o básico da ideologia desenvolvimentista, perdiam campo em relação aos aspectos ideológicos que operavam na esfera do imaginário. Para conseguir êxito nas áreas sociais e econômicas, o governo inevitavelmente precisava enfrentar as questões ideológicas que o contexto de Guerra Fria evidenciava e marcar de forma clara o seu posicionamento diante da "velha ameaça vermelha". 


\section{Notas}

${ }^{1}$ Especialista em História Cultural pela Universidade de Brasília e em História do Brasil Contemporâneo pelas Faculdades Integradas - UPIS. Professora de História da Secretaria de Educação do Distrito Federal. E-mail: elienegomessilva@ig.com.br

${ }^{2}$ Discurso de Juscelino Kubitschek. Rio de Janeiro, 04/11/1956 pela Rede de Radiodifusão da "Voz do Brasil.” In Juscelino Kubitscheck de Oliveira. Discursos 1956. op. cit., p. 352

${ }^{3}$ Sobre a cassação do registro do PCB, ver: PCB - Processo de cassação do registro (1947). Belo Horizonte: Aldeia Global, 1980; Elizeu Pacheco. O Partido Comunista Brasileiro (1922-1964). São Paulo: Alfa- Ômega, 1984.

${ }^{4}$ Cf. Jacob Gorender em entrevista feita por Waldir José Rampinelli, em São Paulo, no dia 09 de abril de 2002. Publicada em: Revista Brasileira de História. Vol. 23, nº 45, São Paulo, julho de 2003.

${ }^{5}$ Carlos Lacerda. Tribuna da Imprensa, 05 de outubro de 1955 apud Thomas Skidmore. op. cit., p. 188.

${ }^{6}$ Documento expedido à imprensa em 01/09/1955 pelo arcebispo de Diamantina, José Newton Batista. Arquivo Ernani do Amaral Peixoto/ eap.an.1955.01.27- CPDOC/FGV. Disponível em: <www.cpdoc.fgv.br> Acesso em: jan. 2008. (grifos nossos).

${ }^{7}$ Discurso de Juscelino Kubitschek no Senado Norte-Americano. Jornal do Brasil, 06 de janeiro de 1956, p. 07 apud Pio Pena Filho. O Brasil e a descolonização da África nos anos Kubitschek (1956-1961): Ensaio de mudança. Brasília, 1994, p. 79. (Dissertação de Mestrado, UNB).

${ }^{8}$ Discurso do presidente Juscelino Kubitschek, em 03 de fevereiro de 1956, em companhia do vicepresidente dos Estados Unidos da América, Richard M. Nixon. In Juscelino Kubitschek de Oliveira. Discursos 1956. Rio de Janeiro. Departamento de Imprensa Nacional, 1958, p. 21-22.

${ }^{9}$ Entre 1955 e 1961, entraram no Brasil 2.180 milhões de dólares para investimentos nas indústrias automobilística, de transportes, de eletricidade e de aço. Deste total, 48\% eram provenientes de países europeus, principalmente Alemanha, França, Suíça, Inglaterra e Itália e também do Japão e $42 \%$ dos EUA. Sobre os investimentos estrangeiros no Brasil nos anos JK, ver: Ricardo Wahrendorff Caldas. A política externa do governo Kubitschek e a crise estratégica de Aliado Especial. Brasília: UNB, 1989, p. 214-217. (Dissertação de Mestrado, UNB).

${ }^{10}$ Artigo do Diplomata Celso Antônio de Souza e Silva, sobre a Operação Pan-Americana, publicado no Jornal do Brasil, em 17 de julho de 1959 apud Artigos e entrevistas sobre a Operação Pan-Americana. Rio de Janeiro: Departamento de Imprensa Nacional: Ministério das Relações Exteriores. Seção de Publicações, 1960, p. 14-15.

${ }^{11}$ Juscelino Kubitschek de Oliveira. Carta dirigida ao Presidente Dwight D. Eisenhower, em 28 de maio de 1958. Fonte: CPDOC/FGV- Arquivo Negrão de Lima/nl ad-m 1958.05.28 d2.

${ }^{12}$ Carta do então presidente dos Estados Unidos, Dwight Eisenhower, ao presidente do Brasil Juscelino Kubitschek em resposta à carta de Kubitschek, em 05 de junho de 1958. Fonte: CPDOC/FGV. Arquivo Negrão de Lima/nl ad-m 1958.05.28 d2a.

${ }^{13}$ Discurso pronunciado pelo presidente Juscelino Kubitschek de Oliveira à nação e aos representantes diplomáticos dos estados americanos acreditados junto ao governo brasileiro. Rio de Janeiro, 20 de junho de 1958. Fonte: CPDOC/FGV. Arquivo Ernani do Amaral Peixoto/eap bem, 1958.05.27 Id8 (grifos nossos).

${ }^{14}$ Discurso pronunciado pelo presidente Juscelino Kubitschek de Oliveira à nação e aos representantes diplomáticos dos estados americanos acreditados junto ao governo brasileiro. Rio de Janeiro, 20 de junho de 1958. Fonte: CPDOC/FGV. Arquivo Ernani do Amaral Peixoto/eap bem, 1958.05.27 Id8 (grifos nossos).

${ }^{15}$ Discurso de Juscelino Kubitschek, 20 jun. 1958. Fonte: CPDOC/FGV- Arquivo Ernani do Amaral Peixoto/eap bem, 1958.05.27 Id8 (grifos nossos), op., cit.

${ }^{16} \mathrm{Em}$ seu livro A ordem do discurso, Foucault desvenda as relações entre as práticas discursivas e os poderes que as permeiam, percorrendo os diversos procedimentos que cerceiam e controlam os discursos na sociedade. Cf..Michel Foucault.

17 Juscelino Kubitschek de Oliveira. Exposição do Presidente da República às Forças Armadas (17/06/1958). In Resenha do Governo do Presidente Juscelino Kubitschek (1956-1961). Tomo I. Presidência da República. Serviço de Documentação. Rio de Janeiro, 1960. (grifos nossos).

${ }^{18}$ Dom Geraldo de Proença Sigaud. Catecismo Anticomunista. São Paulo: Vera Cruz, 1962, p.13 apud Rodrigo Pato Sá Mota (2002: p. 67). 


\section{Referências Bibliográficas}

ANSART, Pierre. Ideologias, conflitos e poder. Rio de Janeiro: Zahar, 1977.

BACZKO, Bronislaw. "Imaginação social”. In Enciclopédia Einaudi. Vol. 5, Lisboa, Imprensa Nacional/ Casa da Moeda, 1985.

BENEVIDES, Maria Victoria de Mesquita. O governo Kubitschek: desenvolvimento econômico e estabilidade política, 1956-1961. Rio de Janeiro: Paz e Terra, 1979.

CASTORIADIS, Cornélius. A instituição imaginária da sociedade. Rio de Janeiro: Paz e Terra, 1995.

CERVO, Amado Luís (org.) O desafio internacional: a política exterior do Brasil de 1930 a nossos dias. Brasília: Editora da Universidade de Brasília, 1994.

Brasília: IBRI, 2001.

Amado Luís. Relações internacionais na América Latina: velhos e novos paradigmas.

CHAUI, Marilena. Cultura e democracia. São Paulo: Cortez, 1989.

FILHO, Pio Pena. O Brasil e a descolonização da África nos anos Kubitschek (1956-1961): Ensaio de mudança. Brasília, 1994. (Dissertação de Mestrado, UNB)

FOUCAULT, Michel. A ordem do discurso. São Paulo: Loyola, 1996.

GORENDER, Jacob. Gorender em entrevista feita por Waldir José Rampinelli, em São Paulo, no dia 09 de abril de 2002. Publicada em: Revista Brasileira de História. Vol. 23, nº 45, São Paulo, Julho de 2003.

GONÇALVES, Marcos. Os arautos da dissolução: Mito, imaginário político e afetividade anticomunista, Brasil, 1941-1947. Curitiba, 2004. (Dissertação de Mestrado, UFPR)

MARTINHO, Francisco Carlos. Estatismo In Francisco Carlos Teixeira da Silva et al (orgs.). Dicionário crítico do pensamento da direita: idéias, instituições e personagens. Rio de Janeiro: FAPESP, 2002.

MOTA, Rodrigo Pato Sá Mota. Em guarda contra o perigo vermelho: o anticomunismo no Brasil (19171964). São Paulo: Perspectiva, 2002.

ORLANDI, Eni Puccinelli. Análise de discurso. Princípios e procedimentos. São Paulo: Pontes, 2001.

Eni Puccinelli. As formas do silêncio: no movimento dos sentidos. Campinas, SP: Editora da UNICAMP, 1992.

OLIVEIRA, Juscelino Kubitschek de. A marcha do amanhecer. São Paulo: Bestseller, 1962. Editorial, 2002.

Juscelino Kubitschek de. Por que construí Brasília. Brasília: Senado Federal, Conselho

Juscelino Kubitschek de. Exposição do Presidente da República às Forças Armadas (17/06/1958). In Resenha do Governo do Presidente Juscelino Kubitschek (1956-1961). Tomo I. Presidência da República. Serviço de Documentação. Rio de Janeiro, 1960. (grifos nossos)

PÊCHEUX, Michel. Semântica e discurso: uma crítica à afirmação do óbvio. Campinas, SP: Editora da Unicamp, 1995.

PESAVENTO, Sandra Jatahy. História \& História Cultural. Belo Horizonte: Autêntica, 2003. 
SKIDMORE, Thomas. Brasil: de Getúlio Vargas a Castelo Branco, 1930- 1964. Rio de Janeiro: Paz e Terra, 1982.

SWAIN, Tânia Navarro. "Você disse imaginário?”. In Tânia Navarro Swain (org.) História no plural. Brasília: Editora da Universidade de Brasília, 1994.

Artigos e entrevistas sobre a Operação Pan-Americana. Rio de Janeiro: Departamento de Imprensa Nacional: Ministério das Relações Exteriores. Seção de Publicações, 1960.

Recebido em janeiro de 2009. Aprovado em junho de 2009. 